\title{
Politics of belonging in the construction of landscapes: place-making, boundary- drawing and exclusion
}

\author{
Daniel .Trudeau
}

Department of Geography, Macalester College, St Paul, Minnesota

\begin{abstract}
Issues of belonging, exclusion and the creation and maintenance of boundaries have surfaced in recent considerations of the production of space, yet the relevance of boundaries and belonging for understanding the construction of landscape has remained largely implicit. In this paper, I wish to explore more explicitly the connection of boundaries, belonging and landscapes by thinking about how landscapes become spatially bounded scenes that visually communicate what belongs and what does not. My focus is on understanding how landscapes are, in part, constructed through a territorialized politics of belonging-the discourses and practices that establish and maintain discursive and material boundaries that correspond to the imagined geographies of a polity and to the spaces that normatively embody the polity. To explore this relationship, I consider a controversy surrounding the operation of a slaughterhouse in Hugo, Minnesota, which was used extensively for Ua Dab-a Hmong tradition of ritual animal sacrifice. The discourses and practices surrounding efforts to remove the slaughterhouse from Hugo, on the one hand, and to have it remain in Hugo, on the other, offer a case through which to explore the politics of belonging and the boundaries that this creates in constructing landscapes.
\end{abstract}

Tn the past two decades, cultural geographers have turned to explore the ways in $I_{\text {which landscapes serve political purposes. Landscape geographers have rallied }}$ around the theoretical point that landscapes are contrived scenes-(re)produced by power relations through cultural politics and social struggles-that present a particular way of seeing. This scholarship has further emphasized that landscapes often fail to represent the sets of social relations by which they are (re)produced. Cultural geographies of landscapes have subsequently focused on uncovering the social processes which construct landscapes as particular constellations of meaning, aesthetics, values and social prescriptions that become naturalized. Issues of belonging, exclusion and the creation and maintenance of boundaries have surfaced in recent considerations of the production of space, yet the relevance of boundaries and belonging for understanding the construction of landscape has remained largely implicit. ${ }^{1}$ 
In this paper, I wish to explore more explicitly the connection of boundaries, belonging and landscapes by thinking about how landscapes become spatially bounded scenes that visually communicate what belongs and what does not. My focus is on understanding how landscapes are, in part, constructed through a territorialized politics of belonging. By 'politics of belonging' I mean the discourses and practices that establish and maintain discursive and material boundaries that correspond to the imagined geographies of a polity and to the spaces that normatively embody the polity. By exploring the relationship between these concepts, I hope to make a contribution to theoretical perspectives on how landscape, defined as a contrived scene, provides a powerful means for bounding places and enforcing particular ideas about belonging to a polity and its embodied spaces.

To explore this relationship, I consider a controversy surrounding the operation of a custom slaughterhouse in Hugo, Minnesota, which was used extensively for Ua Dab, which is a Hmong tradition of ritual animal sacrifice. The presence of the slaughterhouse and the very different sets of human-animal relationships it presented in Hugo became the subject of a protracted struggle in which a group of Hugo residents and the city council were able to excise the slaughterhouse. The discourses and practices surrounding efforts to remove the slaughterhouse from Hugo, on the one hand, and to have it remain in Hugo, on the other, offer a case with which to explore the politics of belonging and the boundaries that they create in constructing landscapes. Before I elaborate the substance of this case, I want to describe in greater detail the ways in which I am approaching landscape and belonging.

\section{Grounding the landscape idea}

Landscape is a visual idea that structures a perspective about social relationships and how land should be used in a particular place. ${ }^{2}$ Landscapes thus offer a perspective of a particular territory and the community relations and identity of the polity associated with that territory. ${ }^{3}$ Like Lefebvre's category of abstract space, landscapes offer a whole scene in which certain material and discursive boundaries are constructed and seem stable, such that power hierarchies are evident and uncontested, and that particular arrangements of values, aesthetics and behaviour are considered normal or natural. ${ }^{4}$ Land-use zoning ordinances offer a concrete way to discuss landscapes and their inherent boundaries.

Land-use zoning ordinances are normative prescriptions about how land in a particular segment of space may be used, who should be present, and how it should appear. ${ }^{5}$ Zoning classifications effectively create spatial categories of acceptable social behaviour and visual aesthetic. ${ }^{6}$ Such classifications are also a useful resource to regulate space so that the material content within the boundaries of the zone represents the abstract and normative relations inherent to the particular classification. ${ }^{7}$ For example, land-use zoning has been used by municipal governments in the US to enforce racial homogeneity at the neighbourhood level. ${ }^{8}$ Furthermore, zoning ordinances have been instrumental in criminalizing certain behaviours that are 
associated with particular groups, effectively enforcing the legal exclusion of such groups from designated spaces. ${ }^{9}$ In this way, land-use zoning imposes a particular geographical imagination on a bounded segment of space. ${ }^{10}$ Land-use zoning is thus an important aspect in the construction of landscapes in contexts of human settlement. Moreover, this instantiation of landscape makes explicit the importance of boundariesand the regulation of characteristics supposedly contained within them-to the construction of landscape.

\section{Politics of belonging and human-animal relationships}

Belonging is central to understanding the social control of space. ${ }^{11}$ It is often discussed in terms of membership to a polity. ${ }^{12}$ To belong in this sense requires a sharing of characteristics and attributes essential to the identity of a polity. Belonging necessarily entails bounded classifications of characteristics associated with membership in a polity. ${ }^{13}$ Insofar as polities are associated with distinct territories, whether imagined, metaphorical or material, belonging is inherently spatial. Thus, to belong to a polity is also to belong to its associated places. Membership in a (territorialized) polity is often a political issue, since the opposite of belonging is exclusion. ${ }^{14}$ The politics of belonging (and exclusion), then, play a significant role in the production of social spaces such as landscapes and place. Appraisals of human-animal relationships are often at the crux of questions of belonging, and matter significantly to the control and production of space. $^{15}$

The classification of (in)appropriate human-animal relationships is important to how communities define themselves. ${ }^{16}$ From a historical perspective, Philo has shown that corporeal relationships with livestock have been pushed to the territorial margins of cities such as London and Chicago in efforts to shape these cities into morally decent, safe and salubrious places. ${ }^{17}$ Furthermore, Philo has discussed how the displacement of animal slaughter and milk production are part of a project involving the long-term splitting apart of the urban and the rural as distinctive entities conceptually associated with particular human activities and attributes (the industrial and civilized city, the agricultural and barbarian countryside)'. ${ }^{18}$ In the current context of immigration patterns in the US, where the arrival of peoples with decidedly different ideas about acceptable human-animal relationships challenge settled notions about nation, the labelling of certain human-animal relationships as unacceptable or foreign is a significant and concrete way in which 'others' are spatially constructed. ${ }^{19}$ This construction is spatial because classifying certain human-animal relationships, such as animal sacrifice, as fundamentally different, foreign and unacceptable is a political manoeuvre intended to remove putatively contradictory characteristics and behaviours from a polity and its associated territory. ${ }^{20}$ The politics of belonging thus creates boundaries that are at once social and spatial. ${ }^{21}$ The following discussion of the controversy in Hugo offers an opportunity to examine the importance of the politics of belonging to the construction of landscape. 


\section{The landscape of Hugo}

On 15 May 2000, Seng Lee, a Hmong immigrant, stood before the Hugo city council in a public hearing to defend his custom slaughterhouse against a restrictive zoning ordinance that the council was considering. ${ }^{22}$ The ordinance would effectively require Lee to close his slaughterhouse in Hugo, a town of about 6500 residents located on the periphery of the Minneapolis-St Paul metropolitan area. ${ }^{23}$ The council rationalized closing Lee's slaughterhouse because it presented a fundamental land-use conflict: it argued that Lee was using his property for a commercial activity in a district that had been zoned for agricultural and rural residential use. Lee operated the slaughterhouse both to process meat for sale and to provide a venue for $U a D a b .{ }^{24}$ Lee counter-argued that he used his land for religious purposes.

In the several months leading up to the 15 May 2000 public hearing, residents near the slaughterhouse and other Hugo residents expressed a great deal of outrage over the slaughterhouse, articulating that it was out of place and conflicted with the character of Hugo. Lee and his supporters argued that the slaughterhouse facilitated religious practice, as it provided a place essential for $U a D a b$, and thus had a right to remain. The group of residents seeking to remove Lee's slaughterhouse from their neighbourhood ultimately appealed to the city government for assistance. This controversy became a cultural and political one. It hinged upon how to categorize Lee's slaughterhouse in relation to the 'agricultural' classification in which it was operating. Indeed, this controversy, and the process through which it was dealt, highlights the connection between a polity's identity and the spaces in which it is represented and (re)produced.

\section{Hugo as a rural place}

Located $29 \mathrm{~km}$ from downtown St Paul, Hugo is at the urban frontier of the Twin Cities metropolitan area and is struggling to maintain a rural character. Historically, the town's economy has been primarily agricultural. As the metropolitan area has grown to include Hugo in its outer suburbs, Hugo's economy has become more diverse. While the town has developed a commercial district in its centre, the outer areas of Hugo have been designed to reflect its rural roots. The closely spaced single and multiple family housing structures in the relatively dense centre of town give way to forested land, agricultural fields and few built structures. This outer part of Hugo is used primarily for hobby farms, cultivation and livestock grazing. This is where Lee's slaughterhouse was located. Figures 1 and 2 offer representations of Hugo's landscape in these areas. Residential uses are permitted in this area of Hugo, but housing structures cannot exceed a density of one per 10 gross acres. ${ }^{25}$ Still, Hugo had only 14 farms in 2000 . Most of this outlying area was used for low-density residential living permitted in the agricultural designation. These land-use rules intend to keep a rural feel and pastoral character to Hugo, which many residents of Hugo and other municipalities in the metropolitan area celebrate. ${ }^{26}$

Hugo is also a white place. It was initially settled by French Canadian immigrants, and has remained white to the present day. ${ }^{27}$ According to the 2000 census, Hugo's 


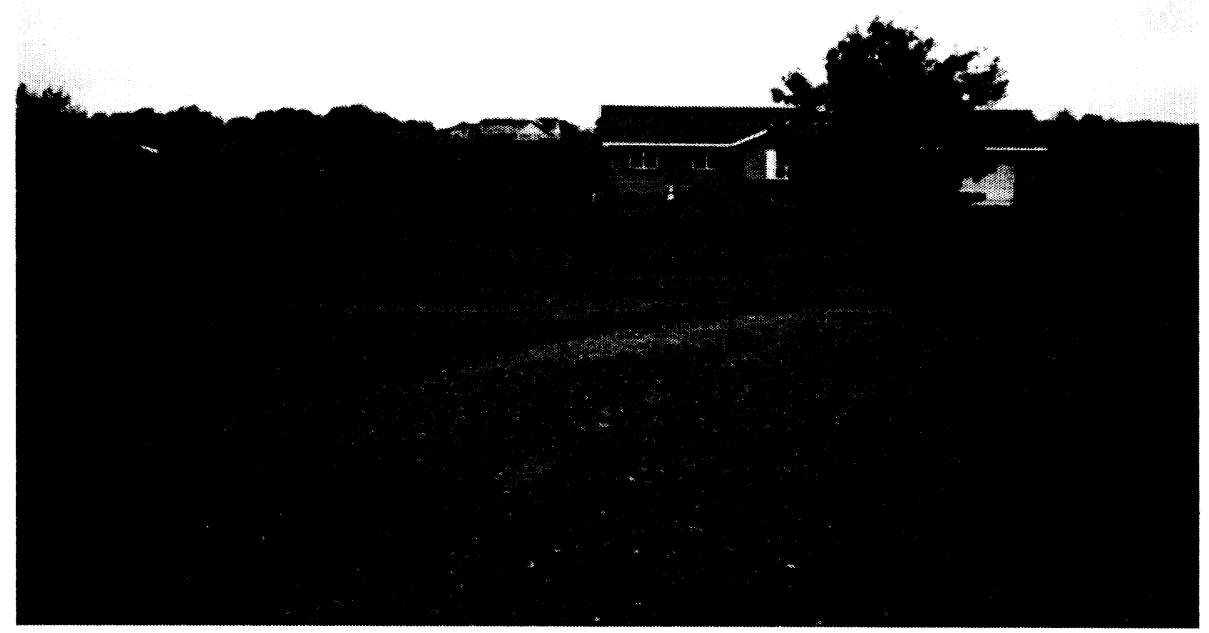

FIGURE 1 Low-density housing and wide open spaces help to evoke a pastoral character in the rural-residential spaces of Hugo. (Photograph by the author.)

population is 97.2 per cent white and 1.4 per cent Asian, with 1.4 per cent of the total population claiming Hispanic/Latino heritage. ${ }^{28}$ It is difficult to know accurately the number of Hmong individuals among the total Asian population in Hugo. However, estimates presented in the media figure Hugo's Hmong population to less than $100 .{ }^{29}$ In this context, Hmong and other Asians are obviously in the numerical minority. Moreover, to the extent that Hmong in Hugo are seen as representing cultural differences, practices like ritual animal slaughter may be seen by the dominant host society as disrupting the sense of place and rural authenticity that many in Hugo imagine and that has been codified in the agricultural and rural-residential zoning of land in Hugo.

Hugo represents a specific notion of ruralness that can be seen in its approach to animal slaughter. Until 2000, animal slaughter was an activity that occurred but had not been regulated by municipal government in Hugo. The city lacked a specific zoning ordinance that regulated the location and operations of animal slaughter within its borders. One of the long-standing assumptions in Hugo was that animals could be slaughtered for personal use, and no permits were required for such small-scale practices. Moreover, the presence of livestock on the land ensured at least a modest need for the processing of animals into food and other useful products. In fact, the few custom slaughterhouses that have operated in Hugo existed without issue prior to the controversy over Lee's establishment. The activities associated with Seng Lee's slaughterhouse challenged the unwritten, laissez-faire attitude towards animal slaughter in Hugo, and revealed the existence of social and spatial boundaries in the process. 


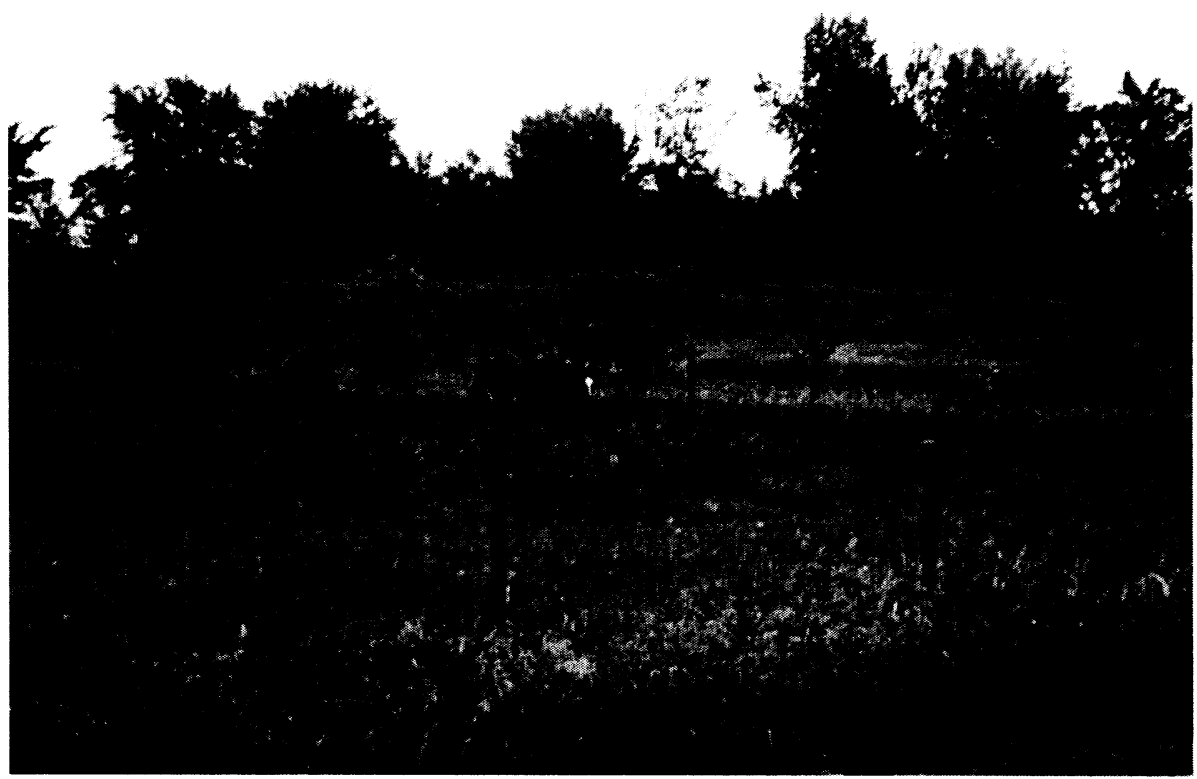

FIGURE 2 Livestock on hobby farms also contribute to a rural sense of place in Hugo. (Photograph by the author.)

\section{Lee's slaughterhouse and Ua Dab}

In September 1999, Seng Lee purchased a 20 -acre property, including a building and equipment for animal processing, located in Hugo's agricultural district. Lee had purchased the property from Xiong Ly, who had owned and used the property for animal processing since 1992. Under Ly's direction the slaughterhouse received a number of complaints, but nothing to the degree that made it a subject of controversy. Soon after Lee purchased the property, he increased activity there significantlyslaughtering about 45 animals a week-which consequently drew many people to his property. ${ }^{30}$

People travelled to Lee's property for two distinct reasons. On the one hand, Lee received livestock, including cattle, hogs, goats and chickens, which he slaughtered for his customers. His customers were primarily Hmong and Muslim East African (i.e. Somali, Eritrean, and Ethiopian) migrants from around the Twin Cities metropolitan area who preferred to consume fresh meat from recently killed animals-a commodity that is popular among many members in the Somali and Hmong communities in the Twin Cities, but is not readily available in local supermarkets. ${ }^{31}$ The few slaughterhouses in the Twin Cities that have worked to meet demand for this product have failed (one slaughterhouse that did operate to meet this demand had caught fire, presumably through arson, early in 2000). ${ }^{32}$ In 2000, the Twin Cities were host to approximately $42000 \mathrm{Hmong}$ and 17000 East Africans. ${ }^{33} \mathrm{I}$ know of no information that would indicate 
what proportion of these populations seeks fresh meat. I think it safe to assume, however, that there was a significant demand for the meat-processing services that Lee provided. These customers travelled to Lee's property, sometimes bringing their own livestock, where animals were killed and butchered by Lee and the processed meat taken away by the customer. ${ }^{34}$ In some cases, customers would use Lee's property to slaughter the animals themselves. Many of Lee's Muslim customers followed this later scenario in order to prepare Halal meat. ${ }^{35}$.

On the other hand, Lee allowed his property to be used for Ua Dab or ritual animal sacrifice. Ua Dab is an animistic tradition often involving animal sacrifice that is performed in some Hmong communities to favour safe passage through life events that are significant in traditional Hmong cosmology, such as birth, death and illness. ${ }^{36}$ Animal sacrifice is a small but necessary part of the ceremonies. ${ }^{37} \mathrm{Ua}$ Dab rituals are clan events, which consequently bring together numerous families and as many as 150 persons, sometimes more. ${ }^{38}$ Thus, when Lee hosted Ua Dab ceremonies, attendees would park as many as 50 vehicles on Lee's property and along the public road adjacent to his property. ${ }^{39}$

At the time, Lee's slaughterhouse was in fact one of two places in the Twin Cities metropolitan area that provided a venue for $\mathrm{Ua}$ Dab ceremonies. ${ }^{40}$ A survey conducted by the Wilder Foundation showed that 66 per cent of Hmong respondents in the Twin Cities metropolitan area practice animism and probably participate in rituals involving Ua Dab (the remainder were presumably Christian or not affiliated with a religion). ${ }^{41}$ The relatively high rate of animism practice, combined with the relative scarcity of venues that existed to accommodate Ua Dab ceremonies, helps to understand further why many people travelled to Seng Lee's slaughterhouse, especially from outside Hugo.

Travel to Lee's slaughterhouse led to traffic congestion and parking problems in a part of the town designated for agricultural and rural-residential use. For Lee's immediate neighbours, the increased presence of traffic introduced an urban problem into a putatively rural place. Lee's neighbours began to make complaints about the traffic and animal slaughter to the city council. The number of complaints increased from September to December in 1999. As part of these residents' action, many of Lee's neighbours lobbied for the city council to intervene in the situation, which it did in December 1999.

Soon after Lee purchased the property, he applied in September 1999 to the state of Minnesota's Department of Agriculture for permits and licences to slaughter animals. The department informed Lee that his property was below acceptable standards, and would need several structural improvements before it could meet sanitation standards and become eligible for licensing. ${ }^{42}$ Lee applied to the city of Hugo for the necessary building permits to pour concrete floors and build concrete walls to separate slaughter areas. The City was consequently made aware of how Lee intended to use his property. Of course, the city had already been made aware of residents' complaints about the property, but Lee's application for building permits seems to have provided an opportunity for the city to act. While the city had never regulated animal slaughter, city staff argued that Lee was operating the slaughterhouse illegally, since he had not 
secured a conditional use permit for operating a commercial business on land zoned for residential and agricultural uses.

\section{Ordering the landscape}

In December 1999, the city filed suit to force Lee to cease all activities at the slaughterhouse. ${ }^{43}$ Lee refused to follow the city's orders. He initiated a counter-suit in response, and alleged that the city's action was based on discrimination against both himself and his Asian and African clientele. ${ }^{44}$ Lee further argued that the city's lawsuit represented an affront to Hmong religious freedom, and a threat to the Hmong community's spiritual livelihood.

It is ironic that animal slaughter would be constructed as a problem in a putatively agricultural and rural environment. Yet, there have been other instances of attempts to exclude slaughterhouses from seemingly rural places. Beginning in the 1980s, the US meat-processing industry experienced a wave of restructuring in which leading corporations 'moved plants away from urban centers and union strongholds and brought them to rural communities, closer to cattle and other agricultural inputs'. ${ }^{45}$ As part of the restructuring strategy, many companies called on migrant and immigrant labour to fill the unskilled jobs in the meat processing plants. As a result, many rural communities in states such as Colorado, Iowa, Minnesota and Nebraska have become a magnet for relatively large numbers of foreign-born people from countries in Central America, Eastern Europe and Central Asia. ${ }^{46}$ The arrival of immigrants has provoked xenophobic responses from some of the long-time residents in these communities, including the passage of English-only sign ordinances and other laws that aim to curtail cultural practices that may seem out of place (such as pig roasts, which are a common community event in some Latino cultures). ${ }^{47}$

Seng Lee's slaughterhouse does not fit very well with the restructuring narrative of the meat-processing industry. At first, it seems that Lee's slaughterhouse is not at all analogous to large-scale agribusiness meat-processing plants-Lee does not represent big capital searching out a spatial fix for profit, nor he does he employ a large migrant workforce. His slaughterhouse does, however, draw a relatively large number of immigrants and refugees to an exurban community in Hugo. In this way his slaughterhouse is comparable to the relocation of the meat-packing industry to rural communities, in that it has indeed prompted a clash of cultures in which racism and nationalism often colour public decisionmaking about how to respond to the presence of newcomers, who are often treated as unwelcome outsiders. ${ }^{48}$ Bloom writes about one such clash in Postville, Iowa, and discusses how a seemingly innocuous proposal of land annexation was fraught with racial prejudice and raised as a legal strategy to make newcomers conform to the norms and established values of the host society. ${ }^{49}$ In discussing the case of exclusion in Hugo, I want to explore how land-use ordinances that aim to police the boundaries of Hugo's rural landscape underline a territorialized politics of belonging based on ideas of race, culture and difference. 


\section{Lee's slaughterhouse as a 'transgression'?}

Between December 1999 and May 2000, public discussion about the appropriateness of Lee's slaughterhouse fomented into controversy. The St Paul Pioneer Press and the Minneapolis Star and Tribune, the largest newspapers in the metropolitan area, both covered the ensuing debate. The papers framed the issue as an essential struggle between the right of a community to enforce established norms and the right of newcomers to continue practising their culture. Residents from Hugo and other municipalities wrote letters to the editor to support Lee's or the city's case. In these exchanges it was clear that the identity of a community was at stake: the nature of Hugo, on the one hand, and the right to be Hmong in America, on the other.

\section{The slaughterhouse as out of place}

A number of groups reacted to Lee's slaughterhouse, casting his property and associated activities as a form of trespass. His neighbours objected to the traffic drawn by the slaughterhouse. Travel to and from the slaughterhouse began as early as 4.30 a.m. and lasted until 11 p.m., and was the most intense on Saturdays. ${ }^{50}$ The traffic patterns that emerged around the slaughterhouse conflicted with the pre-established uses. As one of Lee's neighbours explained to a news reporter: 'We've got kids riding up and down the street, and joggers, and people riding horses. There's no shoulder on the street so you've got to walk down the street, and with all that traffic. ${ }^{.51}$

While the increase in traffic was one of the immediate concerns, some of Lee's neighbours also objected to bloody runoff water, visible animal carcasses, the smell of manure and the cries of dying animals. For another neighbour, this visceral scene was so grave they explained that 'on the weekends, I can't stomach it, to go outside' ${ }^{52}$ One resident summarized the general sentiment of residents by arguing that 'the slaughterhouse takes the neighborhood away from the residents, it does not belong in a residential neighborhood'. 53

As the media coverage of this dispute escalated, the place of Lee's slaughterhouse in Hugo had become a matter of public concern. Few metropolitan area residents expressed their discomfort with Lee's slaughterhouse and Ua Dab. Specifically, two individuals wrote letters to the editor expressing their views that the Hmong were not as culturally developed ${ }^{54}$ and that ritual animal slaughter is a 'barbaric custom'. ${ }^{55}$ And a locally based animal rights organization, Defending Farm Animals, Inc., also entered the debate by holding a vigil on State Capitol grounds for animals slaughtered on Lee's property. The group portrayed animal slaughter on Lee's property as unlawful, abusive and inhumane. ${ }^{56}$

The city of Hugo never expressed such reactionary sentiments. In fact, city administrators and officials never broached the issue of Ua Dab when discussing why Lee's slaughterhouse was out of place. ${ }^{57}$ Instead, statements from the city maintained focus on representing Lee's property as a commercial venture that conflicted with the normative activities and land uses in the area. As one of the city 
council members explained, 'A person ought to have an opportunity to make a livelihood. However, when you're operating a commercial activity in a pretty much residential and agricultural area, the two don't mix well. The cultural and religious aspects cannot be ignored. It has to be given consideration. ${ }^{58}$

But the city council did ignore the 'cultural aspects' of the matter. The council articulated that the matter 'isn't an issue of intolerance for religious and cultural expression. The issue is about a system of permits and licenses designed to safeguard public health. ${ }^{59}$ Furthermore, the city avoided discussion of Ua Dab entirely. Perhaps this was a move to avoid a perceived quagmire in multiculturalism or cultural relativism. Regardless, the city continued to frame Lee's slaughterhouse as a transgression of the city's land-use laws. In this way, concerns about cultural differences and racial prejudice were not given standing in the public debate and the city was able to treat the matter essentially as nothing more than a question of land use.

Following this logic, to the city and a group of its citizens Lee's activities had not only crossed a legal boundary, they were also inserting elements contradictory to the rural identity of Hugo. As a city council member explained to a reporter, Lee's slaughterhouse challenged a whole way of life and conflicted with the nature of Hugo:

\footnotetext{
We will preserve the lifestyle we have but recognize that we're not going to allow commercial slaughter in our city in light of our transitional nature. Hugo is firmly in the process of converting to rural residential usage even on agriculturally zoned property. The Muslim community and the Hmong community are looking for a place to [slaughter animals]. Should we allow a custom slaughterhouse to operate in the community, it would open the door to more [of these operations]. ${ }^{60}$
}

City officials thus consistently classified Lee's property as representing a commercial land use that was altogether inappropriate and incompatible with the (normative) rural nature of Hugo. Mention of an unspecified difference in lifestyle in the quoted statement does hint that perceptions of cultural differences are, at least in part, motivating the removal of Lee's slaughterhouse. Furthermore, the inflexible characterization of Lee's slaughterhouse as a commercial activity elides the complexity of the dispute, of which different cultural practices are undoubtedly a part.

\section{In defence of the slaughterhouse}

Lee initially defended his activities from indictment by explaining the role of the slaughterhouse. For him, his slaughterhouse addressed an important market niche: 'The Asians and Africans need it, that's why I exist. ${ }^{61}$ While Lee acknowledged that there was indeed a business aspect to his use of the property, he explained: 'We're not 100 percent a farm operation. At the same time, we're not 100 percent commercial. ${ }^{62}$ Lee also recognized that the slaughterhouse offered an important space for cultural practices of the Hmong. He explained that the slaughterhouse is also 'a cultural thing; this is the only place you can do the [Ua Dab] ceremonies. ${ }^{, 63}$

Lee's clients and leaders from Hmong communities in the wider metropolitan area also spoke publicly, addressing the city council, to argue for the necessity of the 
slaughterhouse. One of Lee's Hmong customers commented on the opportunity that the slaughterhouse presented for procuring fresh meat: "We definitely need places like this. We actually need more places like this. ${ }^{, 64}$ Another slaughterhouse owner in the area defended the placement of slaughterhouses in Hugo and argued that animal slaughter belongs in rural areas: 'You do not want this operation in an industrial park. Where are you going to house the animals? Where are you going to house the people that comè? [Animal slaughter] is still tied to agriculture. ${ }^{, 65}$

Other individuals spoke to the cultural significance of the slaughterhouse. One patron compared the intended closure of the slaughterhouse to 'taking Friday mass away from Catholics'. ${ }^{66}$ One of the editors of Hmong Times, a local newspaper, further elaborated on the cultural significance of Lee's slaughterhouse: 'This is not simply a stockyard or a slaughterhouse. It's very different. To perform these rituals, you have to go to a secret place nobody can see. In Laos, we perform this ritual close to home, but we don't have the capabilities to do that here. ${ }^{, 67}$ To this point, the president of Lao Family Community, a local Hmong cultural organization, added: '[The Hmong] would like to have this farm continue so they can celebrate their culture. Sooner or later you're going to have Hmong people be your neighbors, your coworkers, your friends. The tradition is not going to die out in America. ${ }^{68}$

As the debate over Lee's slaughterhouse developed, the city formalized its lawsuit to shut down the slaughterhouse. The city council also prepared to conclude the matter entirely by passing a land-use ordinance that would prohibit slaughterhouses altogether from operating in Hugo. Lee became exasperated:

I sacrificed everything to do this. Now they are trying to tell me that I can't do it. At first I thought it was zoning, then they said it was a nuisance. Now I understand. It's different. We're different. The city of Hugo is mostly white and here are these Asians and Africans. 'Oh, boy, that's going to bring the value of our property down. ${ }^{69}$

As part of the legal process in passing the land-use ordinance, the council solicited public input on the matter through a public hearing that took place on 15 May 2000. This hearing, in addition to the city council's deliberation, offers further insight into the issues of landscape ordering and belonging surrounding Lee's slaughterhouse.

\section{Reconstructing the Hugo landscape}

The city council decided to remove Lee's slaughterhouse from Hugo because it putatively contradicted the town's rural sense of place. In doing this, the council maintained its classification of Lee's slaughterhouse as a commercial activity. Lee disputed the council's classification and argued that the slaughterhouse must be seen as a place for religious expression. The public hearing oscillated between these two points as neighbours of Lee's slaughterhouse and Hmong individuals echoed familiar standpoints in the debate. Opponents of the slaughterhouse repeated the 'slaughterhouse as commercial activity' theme: 'a slaughterhouse does not belong in a residential neighborhood', ${ }^{70}$ and 'commercial activities should not be allowed in agricultural and 
residential areas. ${ }^{, 71}$ Proponents of the slaughterhouse developed the framing of the slaughterhouse as a space of worship: 'the Hmong people need the slaughterhouse to do their rituals. It's like going to church. If you take away their church, then there won't be any place to do the ceremonies and practice their religion. ${ }^{, 72}$ The exchanges continued for nearly two and a half hours.

In the public hearing the city council also acknowledged that Hugo was experiencing changes and that the town's centre was urbanizing. The council had initially left open the possibility that a slaughterhouse could operate in the central commercial district of the city. The council ultimately elected to proscribe slaughterhouses from Hugo entirely. The council constructed the activities of a slaughterhouse as belonging neither to the present rural character of Hugo nor to the vision of the emerging urban area in the central business district of Hugo.

In the city of Hugo, we really have not ever provided zoning in which [animal slaughter] would be a principal use ... We're looking to bring in a large number of senior citizens' affordable housing units right in our central business district, where we would actually be mixing commercial and senior housing in a single facility. I cannot imagine we would have many senior citizens who would enjoy having a slaughterhouse across the street with truckloads of animals that would arrive between 6 a.m. and 7 p.m.... Most communities, for a reason, do not want this type of business because it's an incompatible use. It's not a good use in any zoning I can think of and it comes back to the point that this is a zoning issue. Let's not muddy the water. $^{73}$

As this council member explained, the removal of Lee's slaughterhouse was based on the idea that the human-animal relationships practised in Lee's slaughterhouse did not belong in Hugo. Furthermore, the city council member maintains that the decision to remove Lee's slaughterhouse is an unproblematic one based exclusively on a zoning or land-use logic. The declaration of 'incompatible uses' in this thinking has nothing to do with discrimination and concerns for religious freedom; indeed, the speaker unequivocally steered justification of the city council's decision away from crossing into the entangled ground that is concerned with racial and cultural equity.

In the end the council presented the decision to prohibit the slaughterhouse as a matter of respect for the identity of Hugo. The mayor articulated that a slaughterhouse 'is not going to work in Hugo ... Re-evaluating what is happening in this community, it's a transition community [to rural-residential use]. Based on the incompatibility of the use for the future of our community, it's not going to work. ${ }^{74}$ In describing their rationale, the council never strayed from the commercial categorization of the slaughterhouse. That is, the council refused to discuss any cultural or religious merits of Lee's slaughterhouse. The council steadfastly maintained that '[this] is about licenses and permits. This is not a tolerance issue. ${ }^{, 75}$

This statement from the council was made in response to ongoing assertions that the proposal to remove Lee's slaughterhouse was motivated by intolerance of traditional Hmong culture and by a sense of xenophobia towards the immigrants and refugees who visited Lee's property. In fact, outside the city hall, a number of individuals had gathered to display placards that communicated a variety of messages that in essence protested the removal of Lee's slaughterhouse (see Figure 3). The unwavering determination of the city council and some of Hugo's residents to deny the role of 


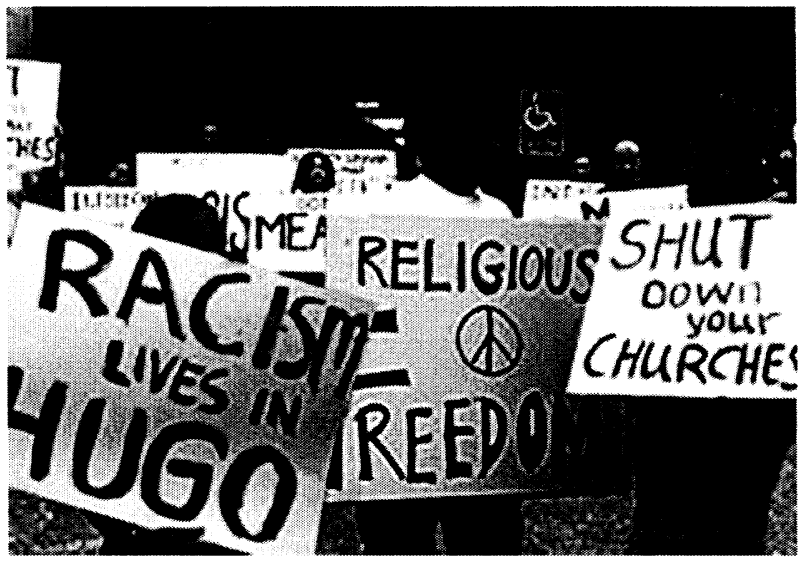

FIGURE 3 Outside the public hearing at the city hall on 15 May 2000, protesters assert that the city council's actions are racist. (Image courtesy of Center for Hmong Arts and Talent, CHAT TV, 'Slaughtered in Hugo', segment.)

racism was on display inside the city hall. In many ways, it seems that the city council had already determined its course of action and was moving to undercut possible criticism of its position. With the different positions in the debate already charted, it further seems that the public hearing was a mere formality.

Lee, obviously frustrated by the continued lack of standing for his argument, castigated the council:

If it's a zoning issue about commercial operations, why aren't the greenhouses, dog kennels, and Christmas tree farmers here? Aren't they commercial businesses too? If it's a health issue, why am I here? That is an issue for the state to consider. [I am here] because I am Hmong. It's my religion. It's my culture. For me to let go of it, that's losing my identity. You say I am an American, but am I really? On paper I'm a United States citizen ... to my neighbours, I'm an Asian guy. ${ }^{76}$

For Lee, the city's decision highlighted exclusive interests. While Ua Dab was not specifically regulated, its importance was not given any standing by the city council. Lee's and some of his supporters' attempts to represent Ua Dab as religious practice deserving constitutional protection was thus undermined. Lee's argument for why the slaughterhouse should have a place in Hugo, and perhaps why Ua Dab should be seen as belonging in America, never gained ground against the arguments for why the slaughterhouse does not belong.

\section{Transgression and the construction of landscapes}

The occurrence of out-of-place phenomena leads people to question behavior and define what is and what is not appropriate for a political setting ... We may have to experience some geographical transgression before we realize a boundary existed. ${ }^{77}$ 
As Creswell explains above, transgressions are inherently geographical. ${ }^{78}$ They are geographical because they are a form of cultural trespass. To be out of place is to violate a community's sense of place. Furthermore, in identifying some social element(s) as a transgression, whether that is a group or a set of behaviours, boundaries are made explicit. After all, a border must exist for there to be some form of trespass. In many ways, the reaction to Lee's slaughterhouse can be seen as a case demonstrating the relevancy of Creswell's framework. The controversy over Lee's slaughterhouse in Hugo also illustrates more than this. This case illustrates that transgressions are moments in which landscapes are (re)constructed in order to fix a particular meaning to a place.

In Creswell's model, transgressions prompt the articulation of doxa (i.e. a set of social rules that are purportedly commonsense) which is then formalized as orthodoxy as a way to ward off future trespass by heretical elements. Transgressions are also consequences of power hierarchies, and occur when a dominant group objects to the actions of a subordinate group. In response to heresy, orthodoxies prescribe a set of relations that are necessary for things to operate smoothly in a polity and its associated territory. Orthodoxies offer a normative geography and a set of social practices that, if strictly followed, can be used to realize the abstract vision. ${ }^{79}$ The theoretical point that I wish to emphasize here is that landscapes, as a particular way of seeing, are visual and spatial articulations of orthodoxy.

\section{Boundaries in the landscape}

In the Hugo case, the revised zoning ordinance represents an instance where orthodoxy was articulated in response to an alleged transgression. The ordinance, which proscribed the slaughter of animals as the principal use of a property, implemented an orthodox set of rules concerning how land in a rural and agricultural district may be used. These rules were intended to restore the town's rural sense of place by codifying what belongs in the district and what could be lawfully excluded. Furthermore, the zoning ordinance creates a normative geography that maps how a bounded segment of space should appear. Thinking about land-use ordinances as an instantiation of landscape, one can see that orthodoxies contribute to the construction of landscapes.

The landscapes that (dominant groups') orthodoxies make have particular boundaries. These boundaries are explicitly recorded on land-use zoning maps. Yet, as the Hugo case shows, dominant groups also assert orthodoxies to control human behaviour and activities within demarcated spaces. In short, orthodoxies draw the line separating what belongs in a polity and its associated territory and what does not. These lines may be drawn between abstract categories, but these categories have spatial referents. These are the boundaries of landscapes. As Gallaher puts it, 'the boundary between "us" and "them" is not just an abstract line upon which mental boundary wars are waged. This boundary is articulated on the ground, in the construction, reconstruction and contestation of spaces. ${ }^{80}$ Applying this logic, the 
removal of Lee's slaughterhouse from the rural spaces of Hugo was an act of purifying the agricultural/rural-residential category and asserting Hugo's particular rural sense of place as much as it was an exercise in delineating the boundaries of where the agricultural category and Hugo's ruralness should be materially represented.

\section{Landscapes and belonging}

Orthodoxies draw boundaries, but they also define what should belong. Belonging refers to an idea of membership in a polity and its associated territory. Those groups located outside the boundaries drawn by orthodoxies are excluded. Landscapes thus are constructed to appear a certain way, and in turn normalize those particular relations, values, aesthetics and ways of seeing the world that orthodoxy represents. Landscapes are visual representations of what belongs. ${ }^{81}$ In others words, landscapes codify membership to a polity and its territory. Landscapes may exclude groups or characteristics from the land, but do so in a non-objective way-those groups or characteristics that do not belong are simply not represented. Only at the margins (i.e. the borders) of landscapes may the 'other' exist. ${ }^{82}$ The representational power of orthodoxy is especially visible in the Hugo case.

Lee's slaughterhouse was constructed as out of place for a number of reasons. The orthodox classification of the slaughterhouse as a commercial activity, first and foremost, was the most discussed. Once classified, the city council and some Hugo residents persistently represented the slaughterhouse as out of place in Hugo. On the one hand, as a commercial activity in an agricultural district, the slaughterhouse disrupted prevailing notions about how a rural place should appear. On the other hand, during consideration whether the slaughterhouse could be placed in Hugo's commercial district, the slaughterhouse introduced an equally unacceptable contradiction for Hugo's vision for its urbanizing areas. The slaughter of animals, and perhaps the Ua Dab rituals that sometimes accompany that activity, were seen as too disruptive and too different to fit into what Hugo's town centre should become. Lee's slaughterhouse and attendant activities were to be excluded because it did not belong in the imagined geography of Hugo.

Lee curiously represented the slaughterhouse as a religious activity to provide a rationale for why his slaughterhouse did in fact belong in Hugo specifically, and in the US more generally. This representation is curious because Ua Dab is a part of traditional Hmong practices. It is not a discrete segment of life; it is simply part of how people live traditional Hmong ways of life. For Lee to frame Ua Dab as a religious practice follows Nagle's notion of a politics of sameness. ${ }^{83}$ This is to say that Lee (and some of his supporters) was appealing to a sense of familiarity, that there are parallels between ritual sacrifice of animals in a communal place and attending mass in a church. This argument for sameness was simultaneously accompanied by an argument for the right to be different-for difference to be accepted. By representing Ua Dab as a religious practice, Lee was also attempting to claim constitutional protections regarding the freedom of religion in the United States. Lee's claims of sameness and a right to be 
different, however, did not grant inclusion of a Ua Dab slaughterhouse within the (dominant) landscape idea of Hugo.

The idea of exclusion of unwanted or undesirable elements is important to understanding the process of constructing landscapes. Denying Lee's claims for belonging highlights the exclusive power of the city council's land-use orthodoxy. As a corollary, constructing the dispute as a function of conflicting land uses undermined the legitimacy of Lee's claims of intolerance and the right to practise religion freely. The city council effectively excluded $\mathrm{Ua} \mathrm{Dab}$, intentionally or not, from the Hugo landscape. The council achieved this through a largely accepted zoning calculus in which particular behaviours and activities were legally proscribed (a calculus that might, in reality, negatively affect certain social groups). The council was able to apply this calculus because the nature of the dispute over the slaughterhouse was consistently framed as a clash of two irreconcilable sets of activities, which allowed the city to treat unproblematically the slaughterhouse dispute as a matter of proscribing behaviours and activities and not a people and their culture outright. ${ }^{84}$ By adopting a rationale that focused on incompatible uses and acceptable activities that agreed with the logic of land-use zoning, the city council was able to ignore the publicly expressed concern about racism, religious freedom and respect for cultural differences. This manoeuvre exemplifies the strategies of the 'new nativism'.

In contrast to the explicit racist and xenophobic sentiment of nativist movements in late nineteenth- and early twentieth-century America, the new nativism denies claims for multiculturalism in an effort to maintain a singular national American culture. ${ }^{85}$ The city council, of course, did not regulate Ua Dab specifically. But, neither did it give any recognition to the value of Ua Dab. By situating the slaughterhouse controversy as a land-use problem, the council avoided the pluralist morass of multiculturalism, and concomitantly imposed a singular view of what belonged in the Hugo landscape. When I visited the site of Lee's slaughterhouse two years after it was shut down, there was no visual record of its presence on the land. Exclusion from the landscape was accomplished through erasure.

Finally, the importance of belonging within the boundaries in landscapes can be addressed by considering Sibley's ideas about the geography of exclusion. Sibley argues that control of space-the definition of what belongs and what does not by creating and policing boundaries-has immediate and real social implications. ${ }^{86}$ The notion that dominant groups exert social control through the purification-and regulation-of space helps our understanding of how landscapes affect social relations. ${ }^{87}$ The efforts of the city council to clarify and enforce the agricultural and rural-residential land-use categories by removing Lee's slaughterhouse are instances of maintaining the homogeneity of such categories. Furthermore, the orthodox response to Lee's slaughterhouse was to reassert the definition of the land-use categories and police their spatial boundaries in an effort to restore the rural sense of place that had supposedly been violated. The regulation of land use in Hugo, rather than the regulation of $\mathrm{Ua} \mathrm{Dab}$ or slaughterhouses specifically, resulted in the removal of the controversial element, Lee's slaughterhouse. The purification of the agricultural and rural-residential land-use categories according to the council's zoning principles 
represents an important part of the (re)construction of landscapes. Indeed, as reifications of cultural unity, landscapes provide a semblance of societal wholeness and order. Landscapes-and the boundaries that define them-further communicate orthodox principles of belonging. The origins of this land-polity definition process, however, can and do become 'terribly mystified' as time passes. ${ }^{88}$

\section{Conclusion: landscapes and place-making}

Landscape and place are two perspectives on the becoming of social spaces. ${ }^{89}$ Landscapes can be thought of as representing an external, detached and objective view of social space. This corresponds to Cosgrove's notion of 'landscape as a way of seeing, ${ }^{90}$ In contrast, a sense of place represents the internal, personal and subjective view of social space. This corresponds to Creswell's application of place as doxa-a taken-for-granted constellation of meanings and appropriate behaviours that define an experience in a social setting. ${ }^{91}$ Both perspectives are fundamentally important to understanding the geography of social experience. The Hugo case shows how landscape may be used to recapture a sense of place threatened by transgression.

In terms of landscape theory, this case shows how, in social practice, transgressions provide a context in which the orthodoxy of dominant groups (re)creates landscape in order to revitalize a sense of community and belonging. In this process, dominant groups codify landscapes and define the terms of belonging. These constructions are also spatialized because the boundaries of landscapes, the line between self and other, are concomitantly made explicit. One can see how certain meanings of a landscape can be elevated to an objective and stable status through the construction of land-use ordinances which map particular meanings onto a territory, which attempt to affect lived experiences on the ground. Yet landscapes are always in the process of becoming, shaped through social struggles and cultural politics. ${ }^{92}$ The Hugo case provides an entrée to understanding how certain meanings of landscape are momentarily stabilized and how alternative meanings become subordinated through political struggle.

There is an important conceptual point to take from this case as well. Geographers have been encouraged to adopt an unbounded ontology of place. ${ }^{93}$ As I have argued, landscapes provide a powerful means of bounding places, as they attempt to fix meaning and identity, and force a sense of coherence on a spatially bounded scene. Furthermore, the effort to use landscape to define place can be seen to be attempts to stabilize the meaning of particular envelopes of space-time. They are attempts ... to impose meaning to be attributed to space, for however long or short a span of time. ${ }^{, 94}$ This is to say that the boundedness of landscapes does not present a conceptual conflict with the movement to adopt a global sense of place. Rather, I argue that landscapes represent socio-spatial practices aimed at fixing boundaries, imposing cultural coherence and stabilizing meaning as a response to the 'inherent unboundedness' and instability of the social world. ${ }^{95}$

Perhaps most importantly, this case also illustrates the strength of landscape as a method of exclusion due to its ability to be a text within which a variety of meanings 
can be scripted, maintained and even hidden. The ambiguous and complex nature of exclusion is part of the reason why landscapes are 'terribly mystified'. In grounding the landscape idea through an examination of the creation and enforcement of land-use zoning ordinances, I hope to have shown that ideas about belonging-i.e. about the proper order of things in a polity and territory-can take on technological legitimacy as they are expressed in terms of legal prescriptions for acceptable behaviour, conduct and activities. When the regulation of the landscape is rooted in the management of permits that attempt to create an environment of compatible uses, concerns about racial discrimination, tolerance of difference and cultural equity can be ignored and dismissed as irrelevant.

The determined construction of Lee's slaughterhouse as a conflicting commercial use allowed the Hugo city council to place the issue of intolerance and discrimination beyond the limits of the matter. By applying land-use logic to evaluate the confrontation between Seng Lee and his neighbours, the Hugo city council members indeed seemed convinced that the issue hinged on nothing more than acceptable uses (in a manner of speaking, it was 'patently obvious' for the council members that landuse compatibility was at the heart of the matter). The detachment of this logic in turn allows the variety of motivations for creating such regulations to go unexamined. As a result, the clear exclusion of 'other' cultural practices can be treated as an unfortunate externality or as an incidental cost of maintaining the proper order of things. After all, if landscapes are the visual articulations of orthodoxy, then they are never constructed in error-by definition, orthodoxy is the 'right' experience or way of doing things. The scripting of the dominant group orthodoxy into the process of landscape (re)construction in Hugo further speaks to the exclusionary power of landscape, and helps to explain why Lee and his supporters ultimately failed to frame the controversy in Hugo as a matter that ought to be evaluated in terms of social justice.

\section{Acknowledgements}

I would like to thank Mona Domosh, Tim Oakes, Betsy Olson, Lynn Staeheli and three anonymous reviewers for their insightful and constructive comments that helped develop this paper. I would also like to thank Noel Lee at the Center for Hmong Arts and Talent in St Paul, Minnesota, for permission to use an image from the video Glass eye/metal face, episode 1: 'Slaughtered in Hugo', which is reproduced in Figure 3 of this paper.

\section{Notes}

1 T. Cresswell, In place/out of place: geography, ideology, and transgression (Minneapolis, University of Minnesota Press, 1996); D. Sibley, Geographies of exclusion: society and difference in the West (New York, Routledge, 1996); D. Newman and A. Paasi, 'Fences and neighbours in the postmodern world: boundary narratives in political geography', Progress in 
buman geography 22 (1998), pp. 186-207; O. Valins, 'Stubborn identities and the construction of socio-spatial boundaries: ultra-orthodox Jews living in contemporary Britain', Transactions of the Institute of British Geographers 28 (2003), pp. 158-75.

2 D. Cosgrove, 'Prospect, perspective and evolution of the landscape idea', Transactions of the Institute of British Geographers 10 (1985), pp. 45-62; D. Cosgrove, Social formation and symbolic landscape (Madison, University of Wisconsin Press, 1998).

${ }^{3} \mathrm{~K}$. Olwig, 'Recovering the substantive nature of landscape', Annals of the Association of American Geographers 83 (1996), pp. 630-53; K. Olwig, 'Representation and alienation in the political land-scape', Cultural geographies 12 (2005), pp. 19-40.

${ }^{4}$ H. Lefebvre, The production of space, trans. D. Nicholson-Smith (Oxford, Blackwell, 1991); D. Mitchell, The lie of the land: migrant workers and the California landscape (Minneapolis, University of Minnesota Press, 1996); E. McCann, 'The cultural politics of local economic development: meaning-making, place-making, and the urban policy process', Geoforum 33 (2002), pp. 385-98.

5 E. McCann, 'Where do you draw the line? Landscape, texts and the politics of planning', Environment and planning D: society and space 15 (1997), pp. 641-61; R. Schein, 'The place of landscape: a conceptual framework for interpreting an American scene', Annals of the Association of American Geographers 87 (1997), pp. 660-80; K. Mitchell, 'Conflicting geographies of democracy and the public sphere in Vancouver $\mathrm{BC}$ ', Transactions of the Institute of British Geographers 22 (1997), pp. 162-79.

${ }^{6}$ For a parallel discussion of how urban and architectural codes are used to structure physical space and regulate social activity, see K. Falconer Al-Hindi and C. Staddon, 'The hidden histories and geographies of neotraditional town planning: the case of Seaside, Florida', Environment and planning D: society and space 15 (1997), pp. 349-72.

7 E. McCann, 'Race, protest, and public space: contextualizing Lefebvre in the U.S. city', Antipode, 31 (1999) pp. 163-184.

${ }^{8}$ C. Silver, 'The racial origins of zoning in American cities', in J. Thomas and M. Ritzdorf, eds, Urban planning and the African-American community: in the shadows (Thousand Oaks, CA, Sage, 1997), pp. 23-42. For an example of how definitions of 'family' in zoning ordinances affect racial segregation at the neighbourhood level, see Y. Rabin, 'The persistence of racial isolation: the role of government action and inaction', in Thomas and Ritzdorf, Urban planning and the African-American community, pp. 93-108.

9 D. Mitchell, 'The annihilation of space by law: the roots and implications of anti-homeless laws in the United States', Antipode 29 (1997), pp. 303-35.

${ }^{10}$ Rose, following Latour, also explains how the planner's land-use map is a visual device that that makes objective and stable certain assemblages of meanings that are otherwise subjective and ephemeral. The land-use map is also an important instrument in delineating the boundaries of abstract space and making them operational on the ground in the landscape. For further discussion of how land-use maps are used in making governable spaces, see $\mathrm{N}$. Rose, Powers of freedom: reframing political thought (Cambridge, Cambridge University Press, 1999).

${ }^{11}$ Sibley, Geographies of exclusion; Cresswell, In place/out of place.

12 J. Crowley, 'The politics of belonging: some theoretical considerations', in A. Geddes and A. Favell, eds, The politics of belonging: migrants and minorities in contemporary Europe (Aldershot, Ashgate, 1999), pp. 15-41; S. Castles and A. Davidson, Citizenship and migration (London, Routledge, 2000).

13 Newman and Paasi, 'Fences and neighbours'. 
${ }^{14}$ C. Nagel, 'Constructing difference and sameness: the politics of assimilation in London's Arab communities', Ethnic and racial studies 25 (2002), pp. 258-87; J. Perea, 'Introduction', in J. Perea, ed., Immigrants out! The new nativism and the anti-immigrant impulse in the United States (New York, New York University Press, 1997), pp. 1-12.

15 A. Wondrak, 'Seen any wildlife? Community conflict and a struggle for the soul of Estes Park, Colorado', Cultural geographies 9 (2002), pp. 68-94; C. Philo, 'Animals, geography, and the city: notes on inclusions and exclusions', in J. Wolch and J. Emel, eds, Animal geographies: place, politics, and identity in the nature-culture borderlands (London, Verso, 1998), pp. 51 71.

16 Wondrak, 'Seen any wildlife?'; Philo, 'Animals, geography, and the city'; K. Anderson, 'A walk on the wild side: a critical geography of domestication', Progress in buman geography 21 (1997), pp. 463-85; J. Wolch, 'Anima urbis', Progress in buman geography 26 (2002), pp. 721-42; G. Elder, J. Wolch and J. Emel, 'Le pratique sauvage: race, place, and the humananimal divide', in Wolch and Emel, Animal geographies, pp. 72-90.

17 Philo, 'Animals, geography, and the city'.

18 Ibid. p. 60.

19 Elder et al., 'Le pratique sauvage'; M. Griffith, J. Wolch and U. Lassiter, 'Animal practices and the racialization of Filipinas in Los Angeles', Society and animals 10 (2002), pp. 221-48.

20 Elder et al., 'Le pratique sauvage'.

${ }^{21}$ Sibley, Geographies of exclusion.

22 The Hmong are an ethnic group native to Laos who primarily lived in remote and hilly areas of the country. During the 1960s and into the 1970s, they received material support from the US to fight communist forces in Laos and Vietnam. When it became clear that the US would not commit additional resources to fighting the war in Vietnam, the Hmong were left without support and faced retaliation from the communist Pathet Lao regime. In the twilight of the US involvement in the war in Vietnam, many Hmong fled from Laos across the Mekong River into Thailand. The US government recognized the Hmong as political refugees, and the first Hmong people came to the United States in 1975. For further information on the history of Hmong people, see K. Quincy, Hmong: bistory of a people (Cheney, Eastern Washington University Press, 1995); S. Chan, ed., Hmong means free (Philadelphia, Temple University Press, 1994); I. Miyares, The Hmong refugee experience in the United States (New York, Garland, 1998).

232000 Census of population: Summary File 3 (US Census).

${ }^{24}$ For more information about shamanism, or $U a D a b$, in Hmong practice, see the online story 'Ua Dab, the Hmong religion' at Minnesota Public Radio: http://news.mpr.org/features/ 200108/27_goetzk_shaman/sidebar.shtml

${ }^{25}$ Hugo Zoning Ordinance, ch. 320, Comprehensive land-use regulations, Article IV, Section 1045, http://www.ci.hugo.mn.us/Zoning_Ord/TOC.htm

26 'Hugo prohibits custom animal slaughter', Star Tribune (Minneapolis, 6 June 2000), p. 1B; Videotape of Hugo City Council meeting (HCCM), 15 May 2000 (Hugo City Council, 14669 Fitzgerald Avenue North, Hugo, MN 55038; HCCM 5 June 2000).

27 Washington County Historical Society, 'Community histories: Hugo' (2005): http:// wchsmn.org/research/communities

282000 Census of population: Summary File 3.

29 'Hmong, neighbors ponder Hugo zoning', Pioneer Press (St Paul, 31 Mar. 2000), p. 1B.

30 'Slaughterhouse dispute', Star Tribune (Minneapolis, 19 Mar. 2000), p. 1B

31 'State shuts Hmong slaughterhouse in Hugo', Associated Press State and Local Wire (Minneapolis, 8 May 2000), p. 1B. 
32 'Slaughterhouse fire damages buildings, spirit', Star Tribune (23 Feb. 2000), p. 1B.

${ }^{33}$ Hmong Minnesota in Ramsey County (St Paul, Hmong Studies Internet Resource Center 2002): http://store3.yimg.com/I/hmongstudies_1764_1090665; Asians in Minnesota (Minnesota Planning State Demographic Center) 2002, p. 5; 2000 Census of population: Summary File 3.

${ }^{34}$ Ibid.

35 'Hugo sorts out flap over slaughterhouse', Pioneer Press (22 Jan. 2000), p. 8A.

36 J. Lemonine, 'Shamanism in the context of Hmong resettlement', in G. Hendricks, B. Downing and A. Deinard, eds, The Hmong in transition (New York, Center for Migration Studies, 1986), pp. 337-48; X. Thao, 'Hmong perception of illness and traditional ways of healing', in Hendricks et al., The Hmong in transition, pp. 365-78.

37 'Slaughterhouse dispute', Star Tribune, p. 1B.

38 'Hmong-run slaughterhouse angers neighbors', Pioneer Press (5 Jan. 2000), p. 1A.

39 Ibid.

40 'State shuts Hmong slaughterhouse in Hugo', Associated Press (8 May 2000); 'Meat plant comes down to cultural, zoning issue', Pioneer Press (16 May 2000), p. 2D.

41 Speaking for themselves: a survey of Hispanic, Hmong, Russian, and Somali immigrants in Minneapolis-St. Paul (St Paul, Wilder Foundation, 2000).

42 'State shuts Hmong slaughterhouse in Hugo'.

43 'Hugo prohibits custom animal slaughter', Star $\mathcal{E}$ Tribune (6 June 2000), p. 1B.

44 'Hugo sorts out flap over slaughterhouse'.

${ }^{45}$ L. Gouveia and D. Stull, Latino immigrants, meat packing, and rural communities: a case study of Lexington, Nebraska (East Lansing, Julian Samora Research Institute, Michigan State University, 1997), p. 1.

${ }^{46} \mathrm{~K}$. Fennelly and H. Leitner, How the food processing industry is diversifying rural Minnesota, (East Lansing, Julian Samora Research Institute, Michigan State University, 2002), pp. 1-12; E. Schlosser, Fast food nation: the dark side of the all-American meal (Boston, Houghton Mifflin, 2001).

47 Gouveia and Stoll, Latino immigrants, p. 14.

48 C. Conte, 'Strangers on the prairie', Governing magazine 15 (Jan. 2002), pp. 29-33.

49 S. Bloom, Postville: a clash of cultures in heartland America (San Diego, CA, Harcourt, 2000).

50 'Hugo prohibits custom animal slaughter'.

51 'Hmong-run slaughterhouse angers neighbours'.

52 'Hmong, neighbors ponder Hugo zoning'.

53 HCCM 15 May 2000.

${ }^{54}$ Letters to the editor, Pioneer Press (24 May 2000), p. 14A. The full text of this letter reads: 'Hugo is a lovely city. It's the kind of town you would raise your family in and be all the better for. The impact a slaughterhouse is having on the small town can be felt in the hearts of the Minnesotans that hear the stories of what is going on in that small farming community. The neighbors who can distinguish the cries of animals dying - that is heart wrenching. Perhaps that is because we have a more developed sense of understanding, and our compassions reach far beyond humanity. Maybe it's not that easily understood because our religion does not condone cruelty, nor does it require the sacrifice of any animal. While we cannot tamper with one's right to choose religion and its practice, we can require that immigrants be prepared to abide by our laws, and come to terms with the fact that some things just cannot be done here regardless of religion.'

55 Letters to the editor, Pioneer Press (20 May 2000), p. 13A. The full text of this letter reads: 'Such inhuman treatment of any animal should not be permitted in a civilized society. If these immigrants want to become United States citizens, they must leave those barbaric customs 
behind. As of now, they are certainly not an asset to the United States... Their barbaric customs and rituals must be left back in their Asian countries. Torturing animals such as this is inexcusable and should not be condoned in any way as a religious ritual. If they want so badly to become American citizens, they should live in a respectable way that honors the country to which they came. Shame on all these Asian barbarians.'

56 'Vigil for Hugo slaughterhouse animals to take place on state capitol steps', Defending Farm Animals, Inc., News Release, 27 Apr. 2000, www.defendingfarmanimals.org, PO Box 17224, Minneapolis, 55417.

57 Although one council member did express hope that 'the Hmong could treat the animals better': HCCM 15 May 2000.

58 'City wants to shut down Hmong-operated slaughterhouse', Associated Press State and Local Wire (5 Jan. 2000).

59 'Hugo sorts out flap over slaughterhouse'.

60 'Hmong, neighbors ponder Hugo zoning'.

61 'Slaughterhouse dispute'.

62 'Hmong-run slaughterhouse angers neighbors'.

63 'Hugo sorts out flap over slaughterhouse'.

64 'Hugo prohibits custom animal slaughter'.

65 'Hugo sorts out flap over slaughterhouse'.

66 Ibid.

67 Ibid.

68 'Hmong, neighbors ponder Hugo zoning'.

69 'Hugo prohibits custom annual slaughter'.

${ }^{70}$ HCCM, 15 May 2000.

71 Ibid.

72 Ibid.

${ }^{73}$ HCCM, 5 June 2000.

${ }_{74}$ Ibid.

${ }^{75}$ HCCM, 15 May 2000.

76 Videotape of Hugo City Council meeting, 15 May 2000.

77 Cresswell, In place/out of place, p. 22.

78 Ibid.

79 Valins, 'Stubborn identities'.

${ }^{80} \mathrm{C}$. Gallaher, 'Identity politics and the religious right: hiding hate in the landscape', Antipode 29 (1997), p. 262.

81 Olwig, 'Recovering the substantive nature of landscape'.

82 R. Wilton, 'The construction of difference: space and psyche in the landscapes of exclusion', Geoforum 29 (1998), pp. 173-85; H. Van Houton and T. Van Naerssen, 'Bordering, ordering, and othering', Tijdschrift voor Economische en Sociale Geografie 93 (2002), pp. 125-36.

83 Nagel, 'Constructing difference and sameness'.

84 There is a parallel here to Gallaher's writing on the conservative politics of Liberty University, which she argues hides a hatred of difference in the constructed landscape of the university by proscribing undesirable characteristics associated with unwelcome groups, such as homosexuals and radical feminists. In this way, Gallaher argues, a fundamentalist Christian identity is legitimated politically and spatially in the landscape of Liberty University such that potentially disruptive challenges to that identity can be removed through accepted means of discipline and exclusion. For further discussion, see Gallaher, 'Identity politics'. 
85 L. Chavez, 'Immigration reform and nativism: the nationalist response to the transnational challenge', in Perea, Immigrants out!, pp. 61-77; J. Feagin, 'Old poison in new bottles: the deep roots of modern nativism', in Perea, Immigrants out', pp. 13-43.

86 D. Sibley, 'The problematic nature of exclusion', Geoforum 29 (1998), p. 120; Sibley, Geographies of exclusion; D. Sibley, 'Survey 13: the purification of space', Environment and planning D: society and space 6 (1988), pp. 409-21.

87 Sibley, Geographies of exclusion.

${ }^{88}$ Mitchell, Lie of the land, p. 2. Mitchell writes that landscapes are at once 'patently obvious and terribly mystified'. They are obvious in the sense that they readily communicate a whole scene in which certain material and discursive boundaries are constructed and seem stable, where particular power relations are evident and yet uncontested, and where a particular arrangement of values, aesthetics, and behavior are considered normal. Yet landscapes are mystified because it is in no way obvious how these aspects of the land have come to be decided and constructed as they are deployed. Because the material landscape and all of the discursive content it represents are presented as natural and often static, the origin and ephemera of its particular representations are never readily apparent.

89 Schein, 'The place of landscape: a conceptual framework for interpreting an American scene'.

90 Cosgrove, Social formation.

91 Cresswell, In place/out of place.

92 McCann, 'The cultural politics of local economic development: meaning-making, placemaking, and the urban policy process'.

93 See e.g. D. Massey, 'A place called home?', New formations 17 (1992), pp. 3-15; A. Pred, Place, practice and structure (Totowa, NJ, Barnes \& Noble, 1986); J. Duncan and N. Duncan, 'Culture unbound', Environment and planning A 36 (2004), pp. 391-403.

${ }^{94}$ D. Massey, Space, place, and gender (Minneapolis, University of Minnesota Press, 1994), p. 5.

95 Duncan and Duncan, 'Culture unbound'. 